\title{
Remote communication for people with disabilities: Support persons' views on benefits, challenges, and suggestions for technology development
}

\author{
Margret Buchholz ${ }^{\mathrm{a}, \mathrm{b}, *}$, Kristina Holmgren ${ }^{\mathrm{a}}$ and Ulrika Ferm ${ }^{\mathrm{b}}$ \\ ${ }^{a}$ Department of Health and Rehabilitation, Institute of Neuroscience and Physiology, Sahlgrenska Academy, \\ University of Gothenburg, Göteborg, Sweden \\ ${ }^{\mathrm{b}}$ DART Centre for AAC and AT, Queen Silvia Children's Hospital, Sahlgrenska University Hospital, Göteborg, \\ Sweden
}

\begin{abstract}
.
BACKGROUND: Being able to communicate through digital channels is a prerequisite for participation in contemporary society. People with communicative and cognitive disabilities (CCDs) face challenges in this area, thus often being excluded from participating fully in society.

OBJECTIVE: This qualitative study focuses on aspects of technology that facilitate or impede remote communication in people with CCDs.

METHODS: Support persons for people with CCDs $(N=21)$ participated in five focus groups to discuss this topic.

RESULTS: Data analysis yielded two themes: using standard technology and using assistive technology. Each theme encompasses categories describing aspects and functions of technology that facilitated or impeded remote communication. The support persons felt that standard and assistive technology needed possibilities for personalization for ease and accessibility. There is a need for increased compatibility between assistive and standard technology and between platforms. Remote communication technology must be made more accessible and easier to use for both people with CCDs and those in their networks.

CONCLUSIONS: The study provides an overview and illustrative examples of how technology can enhance or hinder remote communication. We offer suggestions on how technology can be developed to meet the specific needs of people with CCDs and simplify remote communication for them.
\end{abstract}

Keywords: Augmentative and alternative communication, cognitive impairment, communication, computer access, information technology and telecommunications, universal design

\section{Introduction}

Remote communication is communication between people who are not physically in the same place. It can

\footnotetext{
${ }^{*}$ Corresponding author: Margret Buchholz, DART Centre for AAC and AT, Queen Silvia Children's Hospital, Sahlgrenska University Hospital, Kruthusgatan 17, 41104 Göteborg, Sweden. Tel.: +46 3134208 06; Fax: +46 311558 29; E-mail: margret.buchholz @ vgregion.se.
}

be synchronous, like phone calls and video calls, or asynchronous, like texting (SMS), email, and various online communication services. Being able to communicate remotely through digital channels is generally seen as a prerequisite for participation in contemporary society. The right to communicate is a fundamental human right according to the United Nations and the American Speech-Language-Hearing Association [1-3]. In Sweden, where this research was conducted, remote communication is a common means of

ISSN 1055-4181/20/\$35.00 (C) 2020 - IOS Press and the authors. All rights reserved

This article is published online with Open Access and distributed under the terms of the Creative Commons Attribution Non-Commercial License (CC BY 4.0). 
everyday communication. In $2018,93 \%$ of the population aged 16-85 had internet access at home, and 66\% used social media [4].

People with disabilities can have difficulties using remote communication due to a lack of access to standard technology - commercially available off-the-shelf technology for communication, such as smartphones, tablets, and applications [5,6]. Therefore, people with disabilities may need assistive technology, specially designed hardware and software specially to assist with communication, to gain access to remote communication, including the Internet. Assistive technology may also involve accessibility features of standard technology. People who have disabilities affecting their ability to communicate can use augmentative and alternative communication (AAC: i.e., methods to compensate for their restrictions in their ability to produce and comprehend spoken and written communication). It is common for several AAC methods to be combined into individually designed systems involving both low and high technology [1,7]. Such a combination may include both standard technology and assistive technology, (e.g., a standard-technology tablet computer equipped with an assistive device for alternative access and AAC software) [8].

People who have communicative disabilities may also have cognitive problems and difficulties reading and writing. For them, AAC systems may include graphic symbols and text-to-speech for assisted reading $[1,7,9]$. However, those who use AAC and have cognitive problems affecting their ability to read and write find it challenging to handle mainstream digital interfaces due to complex and text-based layouts, thus limiting their access to remote communication $[10,11]$. Among people with speech impairment or cognitive difficulties in Sweden, fewer than half (44\% and 40\%, respectively) claimed that they found it easy to use the Internet [12]. Chadwick et al. [13] describe how people with intellectual disabilities do not have access to internet to the same degree as others and that technology development has bypassed them. Remote communication can reduce isolation by increasing social contact, independence, confidence, and participation [14-16]. However, in a recent study by Alfredsson Ågren et al., only 52\% of the participants with intellectual disabilities reported that they had contact with friends over social media compared to $93 \%$ of the reference group without disabilities [17]. Selfdetermination (sometimes described as autonomy or independence) is the ability and freedom to make one's own choices, and it is essential for optimal function- ing and well-being as well as a prerequisite for societal participation [18]. In the International Classification of Functioning, Disability and Health (ICF), participation is described as a person's involvement in different life areas [19]. Those who lack access to remote communication may end up on the wrong side of the "digital divide" and become more excluded from today's digitalized world $[5,13,20]$. There is a need to remove the obstacles to internet access for people with disabilities and to strive for universal web access to enable more equal participation for everyone [21,22].

There is a lack of research focusing on the need for remote communication of people who have not only communication difficulties but also cognitive problems affecting their ability to read and write. There is also a lack of research into the development of remote communication technology meeting the needs of people with communicative and cognitive disabilities (CCDs) who find it hard to use such technology in its present form [14,23-25]. In a previous study [10], people with CCDs were interviewed and asked to share their experiences with remote communication in daily life. However, due to the participants' limited technology experience and cognitive difficulties, it was difficult for them to reflect upon remote communication technology. Using new technology is not only a matter for the users themselves, but also for support persons like family members [26] and professionals [27] who are expected to assist the users. As support persons are present during the everyday lives of people with CCDs and have first-hand experience with how the people they support use remote communication, support persons are in a unique position to share their views on factors that can enable self-determination and participation.

The present study's aim was to describe support persons' views on aspects and functions of remote communication technology that could enable and stimulate independent communication, self-determination, and participation for people with CCDs that affect their literacy, which, to some degree, interfered with using remote communication in daily life. The following were the main research questions: (1) What remote communication solutions would work well for people with CCDs that affect their literacy? and (2) What aspects of remote communication would be problematic for people with CCDs that affect their literacy? Data were collected and analyzed from focus groups of support persons. The study concludes with suggestions for improvements to remote communication for further participation for people with CCDs. 
Table 1

Focus group participants in each group, their gender and roles

\begin{tabular}{lcccccc}
\hline & $n=21$ & $\begin{array}{c}\text { Group 1 } \\
n=6\end{array}$ & $\begin{array}{c}\text { Group 2 } \\
n=6\end{array}$ & $\begin{array}{c}\text { Group 3 } \\
n=4\end{array}$ & $\begin{array}{c}\text { Group 4 } \\
n=3\end{array}$ & $\begin{array}{c}\text { Group 5 } \\
n=2\end{array}$ \\
\hline Gender & 4 & 0 & 2 & 0 & 1 & 1 \\
$\quad$ Male & 17 & 6 & 4 & 4 & 2 & 1 \\
$\quad$ Female & & & & & & \\
Role & 10 & 3 & 2 & 3 & 1 & 1 \\
$\quad$ Family & 7 & 2 & 3 & 1 & 1 & 0 \\
$\quad$ Staff & 4 & 1 & 1 & 0 & 1 & 1 \\
Family and staff & & $42-57$ & $30-52$ & $28-55$ & $45-61$ & $51-52$ \\
Age range & & & & & & \\
\hline
\end{tabular}

\section{Materials and methods}

\subsection{Research design}

A qualitative design based on focus groups was chosen to understand support persons' perspectives, views, and thoughts in their role as supporting users of remote communication. Focus groups can be defined as group sessions where people meet to discuss aspects of a certain topic in a focused way under the guidance of an experienced group leader. The method has specific methodological criteria and procedures and is based on five core elements: 1) people interacting with one another; 2) connection and shared experiences; 3) a tolerant environment; 4) empowered participants; and 5) awareness creation [28,29].

\subsection{Ethics}

The project was approved by the regional ethical review board in Linköping (Ref. No. 2015/162 31) before data collection commenced.

\subsection{Participants}

The 21 participants were support persons to people with CCDs which affected their ability to read and write, which, at some level, interfered with using remote communication in daily life. The participants were family members and/or staff who worked in sheltered housing, schools or as personal assistants (see Table 1). Participants were selected on the basis of their experience on the topic and were considered experts in relation to the group leader(s). The formation of the focus groups was based on homogeneity regarding the participants' shared experience of the specific topic and an aim of having variation to allow for contrasting opinions and aspects of the topic. The sample reflected a wide range of experiences relating to users of different ages with different disabilities and types of communication support as well as different relationships to the direct users (i.e., whether they were family members or paid employees).

Five focus groups were scheduled as recommended by previous research [28-30]. Data collection was continued until no new data responding to the research question emerged, which was established after the fifth focus group [28-30]. The aim was to have five groups of six participants, but due to cancellations, there were two to six participants in each group. The people with CCDs of whom the participants were support persons ranged in age from 7-78 years. They had congenital (e.g., cerebral palsy, autism-spectrum disorder) or acquired disorders (e.g., progressive diseases, traumatic brain injuries, and strokes) that had caused a combination of communicative and cognitive difficulties.

\subsection{Procedure}

The participants were recruited through the website of a Swedish regional center for AAC and assistive technology and through seminars, user organizations, and professional networks. Written consent was obtained from all participants. The moderator of the focus-group sessions (the first author) strove for an open and tolerant atmosphere to enable and stimulate discussions around three key questions: (a) What aspects of remote communication technology work well? (b) What aspects of remote communication technology are problematic for people with CCDs? and (c) How should technology be designed to facilitate better remote communication? Each focus group met for one session, each lasting between 67 and 97 minutes. An observer assisted the moderator and took notes. At the end of each session, the focus group discussion was summarized by the observer, and the participants had the possibility to comment. After each session the moderator and observer had a reflection meeting. All sessions, including the reflection meetings, were audio recorded. 


\subsection{Data analysis}

The analysis began at the reflection meetings with the moderator and the observer after each focus-group session. Krueger's analysis guide for focus-group discussions [29] provided the framework throughout the analysis. The audio files of the focus-group sessions and reflection meetings were transcribed verbatim. The transcripts were read, and the audio files were listened to several times to minimize the inevitable loss of information. At first, the raw data were used to understand the meaning of the whole material and identify preliminary themes. Then the raw data were sorted into preliminary themes and into categories within each theme. All of the researchers (co-authors) met to verify the themes and categories. The initial themes and categories were modified to some extent as a result of these discussions.

\section{Results}

The analysis of the focus-group discussions yielded two themes: use of standard technology and use of assistive technology. Each encompassed categories describing aspects of technology that facilitated or impeded independent remote communication, selfdetermination, and participation. The focus groups provided suggestions for the development of remote communication technology that were described in conjunction with each theme. A detailed list of their suggestions for development is presented in Table 2.

\subsection{Use of standard technology}

It was considered important to be able to use standard technology for remote communication. Some functions of standard technology facilitated independent remote communication while others were challenging in terms of understandability, compatibility, and internet access.

\subsubsection{Video calls}

The participants described how video calls enabled independent remote communication and social interaction. Compared with phone calls using only speech, they described how people with CCDs needed less practical support both when placing a video call and during the communication. Those who used AAC and depended on visual communication, such as signing, facial expressions, and gestures were more easily un- derstood by their communication partners while using video calls. It was also possible, although somewhat complicated, to use graphic symbols on a communication board during a video call. Participants suggested the possibility to involve two different camera angles to facilitate the use of communication boards, improving communication further.

For those who had difficulty understanding the concept of remote communication (i.e., that there is a communication partner who is somewhere else and what that means for the interaction), video calls were considered to be a good option. Video calls allowed communication to be synchronous; therefore, the interactions resembled that of ordinary face-to-face communication. In synchronous communication it was easier for people with CCDs to understand with whom they were communicating, the contact was natural, and there was direct feedback.

A: He uses his Skype... Because he signs, video's very useful to him most of the time, he puts the tablet down nearby, and then he can sign.

B: Yes, exactly, having video and using FaceTime, it doesn't matter because my daughter's got no speech at all, but she can nod. And simply being able to do that without any outside influence and being able to see facial expressions and things like that, that means quite a lot. So it's really a big thing, being able to talk like that. (Group 5)

\subsubsection{Asynchronous communication}

The participants described how people with cognitive disabilities benefitted from the delayed interactions typical of asynchronous communication, such as texting, emailing, and messaging functions, including internet chatting. This gave them time to read the message, to reflect on its meaning and on how to compose an adequate answer, and to consult a support person if they were unsure about the meaning of the message or needed help responding adequately. Hence, asynchronous communication could work well for those who find social interactions difficult or need a longer time to construct their messages.

The participants described how systems offering the opportunity to send photos, videos, and audio recordings to one another were usually easy to understand and use. Recorded messages were described as useful, as the users did not need to read or write and could handle the messages more independently. Being able to share pictures on social media was valuable, especially for those with limited access to other means of remote communication. Participants reported that emojis were 
Table 2

Support persons' suggestions for remote communication technology development to meet the needs of people with CCDs

\begin{tabular}{|c|c|}
\hline \multicolumn{2}{|l|}{ Standard technology } \\
\hline \multirow[t]{6}{*}{ General aspects } & All-in-one devices so there is less technology to handle \\
\hline & More opportunities for individualization \\
\hline & Internet of Things to reduce the need for human support \\
\hline & General standard so that all platforms can communicate \\
\hline & Better reliability of technology \\
\hline & Free Wi-Fi everywhere \\
\hline \multirow{7}{*}{$\begin{array}{l}\text { Access to standard-technology } \\
\text { devices }\end{array}$} & Tablets and smartphones that are more accessible for people with cognitive problems and limited literacy \\
\hline & Availability of simpler phones with only the basic, necessary functions \\
\hline & Better sound quality in phones during calls \\
\hline & Easier access to smartphones, tablets, and websites \\
\hline & Easy-to-navigate systems: more intelligible organization of choices on the screen with a good overview \\
\hline & Easy-to-understand organization of applications in devices \\
\hline & Texting available for symbol users \\
\hline \multirow{10}{*}{$\begin{array}{l}\text { Access to websites, services, } \\
\text { and applications }\end{array}$} & Better accessibility for those with cognitive problems and limited literacy \\
\hline & Availability of more limited, easy-to-use interfaces \\
\hline & Fewer pop-ups and notifications \\
\hline & Easier to choose and use symbols and emojis \\
\hline & Availability of information about the meaning of an emoji \\
\hline & Better designed, uncluttered interfaces (objects, colors, order) \\
\hline & Smooth reading with text-to-speech in all environments \\
\hline & Fewer dialog boxes \\
\hline & Easier navigation to return to previous pages in all environments \\
\hline & Symbol databases in standard devices (along with emojis and other graphic symbols) \\
\hline \multirow[t]{4}{*}{ Alternative access } & $\begin{array}{l}\text { Standard devices, such as tablets and smartphones, should be possible to combine with devices for } \\
\text { alternative access }\end{array}$ \\
\hline & Websites must be made accessible for assistive technology \\
\hline & Several camera angles in video calls to involve low-tech AAC \\
\hline & Touchscreens that can be operated with a laser pointer \\
\hline \multicolumn{2}{|l|}{ Assistive technology } \\
\hline \multirow[t]{6}{*}{ General aspects } & Better bridges between assistive technology and standard technology \\
\hline & Assistive technology must enable internet use \\
\hline & $\begin{array}{l}\text { Inclusion of common standard-technology features, such as buttons for sharing to social media, email, or } \\
\text { messaging }\end{array}$ \\
\hline & Assistive technology to build on open-source code \\
\hline & AAC software available on standard platforms \\
\hline & Easy-to-handle AAC software \\
\hline \multirow[t]{7}{*}{$\mathrm{AAC}$ and remote communication } & Easier inclusion of AAC and symbols in remote communication \\
\hline & Seamless switching between using text and symbols \\
\hline & "Premade vocabulary" for remote communication \\
\hline & Faster production of messages \\
\hline & Symbols and text-to-speech in texting, messaging, and online chatting \\
\hline & Message history in texting, messaging, and online chatting \\
\hline & Video calls using AAC software with text-to-speech \\
\hline \multirow[t]{2}{*}{ Alternative access } & $\begin{array}{l}\text { Technology capable of interpreting all user signals in communication in the same way as close family } \\
\text { members do }\end{array}$ \\
\hline & Settings that can easily be adapted to suit changes in day-to-day circumstances \\
\hline
\end{tabular}

particularly useful because the general population uses them, and they are available in many different applications. One downside of using emojis was it could be difficult to understand or interpret the meaning of the emoji. The participants suggested a feature that would present the meaning of an emoji in speech synthesis while users were reading or prior to sending a message, in order to increase the certainty of the emojis' meanings to the users.

A: But that's the advantage of internet chatting, you can sit there discussing, it's not all that direct, someone will say something, and then you can spend some time discussing, "how do you want to respond to this?" It's not direct like if you're on the phone... and you're communicating at your end while the other person's waiting for you to... It's not like that and that's what so great about internet chatting. And you can take a picture of what you're doing instead of saying or writing it.

B: Yes, that's true. That's one aspect.

A: With the picture he sent, it's clearer, so at that 
level of intellectual disability it's fantastic.

C: Yes, of course.

B: I never thought about that, really. That it actually gives you some time to think.

A: Well, the whole internet chatting thing is... great because there are so many choices. There're pictures or speech, and then you can spend some time thinking before you say or do something. (Group 3)

\subsubsection{Ease of use}

The participants described the importance for people with CCDs of having access to digital communication in order to deal with practical matters when contacting banks and healthcare services and booking online services. Complex, largely text-based websites constituted an obstacle for people who had limited literacy and lack functional assistive technology. Some types of standard technology, such as tablets, were perceived as easier to understand and handle compared to computers. The participants pointed out that tablets and smartphones had many accessible functions. For example, using a picture-based address book facilitated communication with members of a person's social network.

However, even tablets were sometimes too complicated to handle. The participants described how having a large number of unnecessary functions and settings complicated the use of remote communication and made it difficult to find one's bearings. Users often accidentally opened a function (a link or an application) and then had trouble finding their way back. In addition, pop-ups and notifications were hard to understand, which caused anxiety and complicated remote communication. Further, handling personal login codes to phones, tablets, or applications were also found to be problematic. The participants described how making a regular phone call on a smartphone was too complicated for some users, who instead preferred products with more limited advanced functionality, such as phones with buttons instead of touchscreens. They pointed out that it was difficult to find standard technology that was easy to handle for people with CCDs.

The participants wanted standard technology to meet the needs of users with CCDs better, so they would be able to use the same equipment and functions as the people around them. In order to meet their needs better, the support persons suggested that systems, applications, and services must be easier to handle and navigate without unnecessary choices, adjustments, and disturbances. According to the participants applications for internet chatting and messaging need to be better adapted to the needs of people struggling with literacy. For instance, they suggested that text-tospeech should be available as a standard choice. Additionally, texting with a smartphone was something that the participants considered to be useful and, therefore, felt should be made easier to utilize.

A: The technology must be made simpler... So they can do something on their own while chatting, something that isn't linked to their assistant, [maybe] pressing the buttons to get that smiley face. Something very simple so that they're more involved themselves.

B: Well, I'm thinking adaptation. That there's got to be settings to adapt the technology to make it easier, you know, instead of having a hundred [smileys] as you said, it's cut down to the ones most commonly used. And if that's wrong, you can press a button once more to get the next batch of ten or so smileys to choose from. That would've been a much simpler technological feature.

C: It would have to be pretty stripped down, you know, the view. Both the interface and the colors and stuff.

B: Not as messy. (Group 3)

\subsubsection{Incompatibility}

One problem described by the participants was that certain applications worked only on specific platforms. This made applications incompatible with each other, and they were unable to communicate with each other. The participants wished there were a general standard to ensure that users were able to communicate with each other despite using different platforms (e.g., Android or iOS). They suggested a development where several standard technology solutions were merged into one, in order to have as few devices and systems as possible, which would be beneficial for people with CCDs.

A: But at the same time, you can't do FaceTime with someone who hasn't got an iPad.

B: No, you can't.

A: Or if they're using Android, then there's no chance. (Group 1)

\subsubsection{Internet access}

The participants discussed how places where people with disabilities spend a great deal of time, such as sheltered housing and daily-activity centers, often lacked an internet connection, hindering remote communication. They suggested that free Wi-Fi access 
should be offered to enable and increase the use of remote communication in all such locations, including nursing homes and public places.

\subsubsection{Use of assistive technology}

Assistive technology was described to enable remote communication, but certain issues restricted these opportunities. The participants described the importance of being able to combine standard technology and assistive technology in order to have access to remote communication. Participants highlighted the fact that there was a need to develop assistive technology further, and they suggested possible improvements.

\subsubsection{Reading and writing support}

The participants described how software that supported reading and writing or converted symbols to text enabled participation in text-based remote communication on the same level as people without disabilities. Messages written with assistive technology were presented as ordinary text, and assistive functions or symbols were not visible to others. For users of symbol-based software, writing and reading emails was the type of remote communication that worked best. The participants called for seamless switching between graphic symbols and text and for the technology to combine the two more efficiently, as users often had to choose one or the other. Furthermore, the participants discussed how low communication speed was an obstacle to those using AAC applications, highlighting the need for faster messaging production in remote communication.

\subsubsection{Hard-to-handle assistive technology}

On a general level, assistive technology was described as hard to handle. AAC technology was said to be complicated for both users and support persons to learn. The participants wanted assistive technology to be easy to use rather than requiring a high level of technology skills.

A: The applications tend to be fairly complicated to handle, and they're not really user friendly. Some of them are pretty difficult to deal with if you're going to develop or adjust them. That's another obstacle. The user-friendliness of the applications that are prescribed or recommended by the rehab services or by speech-language pathologists, it would've been nice if they were easier to access.

B: But that's the kind of stuff you can work on yourself if you get to learn the applications.

$\mathrm{C}$ : Yes, but you've got to poke around in them a little, and they take a while to learn. (Group 2)

\subsubsection{Need for development}

The participants characterized the development of assistive technology as slow and often restricted to older operating systems, and, therefore, not keeping up with the development of standard technology. Some assistive devices did not connect to the Internet at all. They expressed how a lack of up-to-date assistive technology may result in further dependence on others. For example, having a conversation history in a messaging application was found to be very useful, but participants pointed out this was rarely available in assistive technology. This made it harder to understand and remember the content of a conversation, making communication more complicated. Furthermore, users may have to instruct their communication partners on how to adapt their communication in order to fit the user's assistive technology. The participants discussed how AAC software must keep up with the development of technology and work on contemporary platforms.

A: Yes, that would've come in handy because the texting function on the iPad gives you these nice dialog threads, you can kind of see, he said this, she said that. You can't get that in my son's application. B: I think it's really important to get this feeling, "now your speech balloon came in." It's something to do with the distinctness of it, you really put your finger on that, which is more important than you think. I really think that's a good idea.

A: [On the AAC-device] They aren't organized in these nice response threads, and I've had to tell people around us that if he doesn't answer right away, you may have to refresh his memory about the question you answered because then he'll have texted a number of other people in the meantime. (Group 1)

The participants described how changes to the rules on the funding of assistive technology also affected the availability of assistive devices. In addition, assistivetechnology devices sometimes disappeared from the market, which meant useful products and services ceased to exist, leaving users without access to remote communication. The participants suggested assistivetechnology software to be based on open-source code to ensure that if a manufacturer decided to take a product out of production, someone else could start developing and distributing the software, as it would allow users to still access tools that they have spent time learning to use. 


\subsubsection{Interconnectivity to increase access}

The participants discussed the advantages of using standard technology as much as possible but stressed that it was often necessary to combine this with assistive applications and hardware for specific individual needs. Sophisticated alternative access methods often needed to be used with a computer rather than other standard devices, such as tablets and phones. The participants described how there were limits to where and when an individually adapted computer could be used, and this could restrict communication in everyday life. For those in need of AAC, the lack of compatibility between assistive and standard technology was a problem. Additionally, AAC applications often lacked ways of sharing content using social media, email, or texting, meaning that users may have had to find their own creative workarounds to compensate for the lack of interconnectivity, such as by manually copying and pasting messages between applications. Another struggle with lacking interconnectivity was when people with CCDs were using standard-technology video calls together with AAC-software, including graphic symbols and text-to-speech, as they were hard to combine with the available technology. There was a wish that graphic symbols should be available when texting from a smartphone. Support persons thought interconnectivity between standard and assistive technology would enable users to communicate from the same platforms as others, thereby increasing participation in society. In addition, participants described how they themselves were generally more familiar with standard technology and had a better understanding of how to use it, which would then help them assist the people they support to learn to use the new technology faster and more easily.

\section{Discussion}

The first question that this study was intended to answer was what remote communication solutions work well for people with CCDs that affect their ability to read and write. The findings show the importance of being able to use remote communication with standard technology. In particular, two ways of engaging in remote communication using standard technology - (a) video calls and (b) asynchronous remote communication - were described as beneficial in enabling and stimulating independent communication, self-determination, and participation.

Video calls were a good example of how the universal design of a new standard technology worked well for users with and without disabilities. Including many types of visual AAC, as well as body communication, seemed to enhance remote communication. This is in line with the findings of an intervention study involving eight adolescents with disabilities using different means of remote communication. They found video calls that used Skype enabled communication because the visual contact stimulated engagement and made it easier for all parties to understand each other [15]. Alfredsson Ågren et al. showed how video calls are equally used between people with intellectual disabilities and those without [17]. As applications with video calls are becoming more and more common in standard technology it can enable access to remote communication for users who struggle with remote communication in speech and writing.

Asynchronous remote communication was also described to have advantages. It is a well-known fact also discussed in the present study - that it can take a long time to produce messages using communication aids [8]. In the case of asynchronous remote communication, the final message does not reveal the amount of time and energy that was actually spent on producing it nor the employed assistive strategies that were utilized. This may help equalize communication with other people. Previous research has indicated how it can be important for people with CCDs to look or seem like everyone else by being able to use mainstream looking technology $[10,16]$. These findings showed how support persons thought it was important for people with CCDs to be able to participate in online activities and choose their own online persona, including deciding whether or not to reveal their disability $[10,16]$.

The second question to be answered by this study was what aspects of remote communication were problematic for people with CCDs that affect their ability to read and write. When it comes to standard technology, the findings of this study pointed to problems with regard to (a) understandability, (b) incompatibility of technologies, and (c) internet access.

First, standard technology was described as too complicated for many people with CCDs to use due to complicated designs and the need to have good to high literacy skills to use it. Second, the incompatibility of different platforms may cause users with disabilities to communicate only with others who have the same application or service. Otherwise they would have to install and handle several applications, and this may prove too difficult for them. These findings correspond to those from a study by Hynan et al. [11] where users described difficulties in using standard technology and 
managing internet use from assistive devices. Third, limited internet access that impeded remote communication could be due to the inadequate technology standard of the places where people with CCDs spend large parts of their lives. These findings are in line with what has been characterized as a digital divide for people with disabilities $[5,13,21]$. In addition, the results of an Australian study showed how unequal access to capital (economic, cultural, and social) could influence digital inclusion for young people with disabilities [31]. This study also identified problems in the use of assistive technology for remote communication both on its own and in combination with standard technology. Some factors that seem particularly relevant to consider are: (a) issues relating to the use of reading and writing support, (b) problems in handling assistive technology, (c) the need for the further development of assistive technology, and (d) the need for increased interconnectivity.

Communication support, like AAC systems, must be able to meet the need for speed and language accuracy in synchronous remote communication. Strategies to increase speed in communication using AAC have been researched and suggestions for enhancements have been made [32]. These improvements of enhancing communication speed do not seem to have been implemented yet, meaning that the issue of speed and the requirement of writing correctly still impede remote communication [25]. Assistive technology was described as difficult to understand and handle. Considering that this technology is used mainly by people with CCDs themselves and by their support persons, it is noteworthy that experts are often initially required to educate in the use of assistive technology. Light and Mc Naughton [20] pointed out that it is necessary to consider the users' operational competence in order to enable independent communication using assistive technology. Considering that support persons are important in assisting the users in every-day life they need to be able to handle assistive technology without difficulties [26,27].

Findings from this and a previous study have shown how problems arise when technology that users depend on for their daily communication ceases to exist [10]. Previously, certain phones supported graphic symbols and text-to-speech in texting. Use of this feature was shown to increase self-determination and participation in people with CCDs [16,33]. However, owing to a change in the technology towards smartphones, this possibility is no longer available, which clearly represents a step backward in technology development for users with CCDs. This example also shows how the lack of interconnectivity between assistive technology and standard technology can turn the use of everyday means of remote communication into a complex matter. Some users do manage to switch between AAC software and mainstream applications for remote communication or internet browsers, but this is difficult and requires technology skills that not all users or support persons have. In a recent study, young adults with cerebral palsy who used AAC participated in focus groups to discuss their social media experiences, and they highlighted barriers to remote communication, including limitations related to AAC technologies, social media sites, and literacy skills [14].

\subsection{Implications}

The present study highlights the need to improve access to remote communication, which is key for participation in today's digital society $[13,21]$. There is a need for further technical development in order to ensure that communication rights for people with CCDs are fulfilled. The support persons in this study put forward creative ideas about how remote communication for people with CCDs could be improved (see Table 2). Some are discussed below.

\subsubsection{Standard technology}

One conclusion from the focus groups is that there is a need for easier ways to handle standard technology. The participants called for an increased selection of individual settings and functions, while at the same time expressing how they were overwhelmed by the possibilities of technology. It is necessary for developers to work on how to include many functions, meeting a range of individual needs, while at the same time creating devices and applications that are easy to learn and do not force users to navigate an overabundance of functions. There is also a need for general standards. The new Web Content Accessibility Guidelines 2.1 that were issued by the World Wide Web Consortium could resolve several of the issues that have emerged in this study by making the Internet more accessible for users with disabilities [22,34]. The beneficial aspects of video calls and asynchronous communication could be used as good examples and serve as inspiration in the development of other remote communication applications.

The findings of the current study also show that users need devices with other access options besides touchscreens and that they wish for devices with but- 
tons to remain available. Other research has demonstrated that problems using touchscreens can be frustrating to AAC users, and this restricted their access to that technology $[6,10]$. Resorting to older devices to avoid touchscreens is one solution, but this restricts opportunities to benefit from useful smartphone functions. Hence, there is a need for alternative means of access to standard phones and tablets. Developers should look deeper into this to find good options.

Even though video calls make it possible to incorporate several means of AAC, involving communication boards or assistive devices or applications remains a complicated issue. The addition of a second camera angle (perhaps utilizing the existing cameras in the devices) in order to focus on the communication aids and involve the entire AAC system better may enable more comprehensive communication.

The issue of unequal access to capital must be kept in mind in AAC and assistive technology interventions in order to safeguard the communication rights of people with communication difficulties. One way, suggested here, to close the digital gap to some extent is to offer free Wi-Fi access in all environments where people with communication difficulties spend large parts of their lives.

\subsubsection{Assistive technology and interconnectivity}

Assistive technology must keep up better with the development of standard technology, and it must also be easy to combine assistive technology with standard technology for remote communication. AAC software should include better remote communication functions. Texting with symbols is needed, and it should be easy to use text-to-speech and text or graphic symbols in video conversations. Studies suggest that technology development must involve cooperation among individuals with disabilities who use AAC, web developers, developers of AAC software, and clinicians in order to meet the needs of people with disabilities regarding remote communication [14,25,35].

People using assistive technology and their support persons need to feel confident that their communication tools will be available on the market for a long time to ensure they will not suddenly be deprived of their means of communication. One solution suggested here is to base software for AAC users on opensource code. One attempt to do this has been in a European Union project (AEGIS - Open Accessibility Everywhere), which aimed to increase internet access for people with disabilities by creating standards and open-source solutions [36]. Creating open-source code then allows someone else to step in to develop and distribute an application if its original manufacturer decides to take it out of production, thus allowing users access to tools they have successfully learned to use.

\subsubsection{Strengths and limitations of the study}

Research concerning remote communication for people with CCDs commonly focus on specific devices, services or internet use. Considering that people with CCDs may have very restricted access to remote communication, leaving perhaps only one possible channel of remote communication, there is a need for an over-all view on the topic which this study is an attempt to provide $[10,37,38]$. Previous research involving interviews with people with CCDs provided insights into their own experiences with remote communication [10]. However, due to their disabilities and lack of technology experience, it was difficult for them to reflect further on remote communication technology. Support persons meet people with CCDs in daily life and have an important role in assisting the users [26,27]. Their views and ideas expand on previous knowledge, which is a strength of this study.

The focus-group methodology was suitable given the aim of this study. Group processes can encourage participants to express ideas and experiences, and being in a group can help people explore and clarify their views [28]. This is particularly useful in exploring the perspectives of groups that have expert knowledge in a field but are rarely involved in research. Unfortunately, one group only consisted of two participants due to cancellations, which limited the ability to hear others' views and decreased the opportunities for clarification. However, data collection was continued until no new data responding to the research question emerged.

The groups were created with the aim of achieving homogeneity in the specific topic (all being support persons of users of remote communication). From their common experience, the intention was to obtain a varied sample in regard to experiences of users in different situations, as well as a variation among the participants themselves in regard to roles, age and gender. The reason was to achieve sufficient variation to allow for contrasting opinions and aspects of the topic. The focus groups consisted of participants who all had been support persons for people with CCDs who used remote communication. This was done to create enough homogeneity in the group that they could all share similar experiences to engage in meaningful conversation. However, the intention was also to create groups of support persons who had different experiences and 
characteristics (e.g., roles, gender, age) to create potentially differing opinions, which would then provide more in-depth discussions and cover a wider range of topics. While we were able to achieve variations in the groups in terms of roles and age, we were unable to have groups with good gender distribution, and this is one limitation of the study.

The study was conducted in Sweden where internet use is very common among the population [4]. Therefore, the views of the participating support persons may not be representative of those in other countries that have less access to and use of the Internet. However, considering the fast development in communication technology, the high internet use figures seen in Sweden may soon be representative in countries that currently have less access.

\subsection{Conclusion}

The findings show the importance of remote communication technology for people with CCDs, and how the current available technology does help with societal participation. Some aspects of remote communication have been reported to work well, but there are also several areas in need of improvement:

- Technology that is used for remote communication must be accessible and easy to use.

- Assistive technology must be reliable, dependable, and possible to use without disturbances. It must operate without bugs, breakdowns, or a need to reset the device, restart the application, or reload the webpage, for instance, as this is stressful for support persons and often impossible for users to handle themselves.

- There is a need for a range of adaptations and settings that can be individualized to each person's needs, and assistive technology must allow connection with standard technology for remote communication.

\section{Acknowledgments}

The authors wish to thank all the participating support persons for sharing their experiences and contributing their time. This paper was funded by the Promobilia Foundation.

\section{Conflict of interest}

None to report.

\section{References}

[1] ASHA. Augmentative and Alternative Communication (AAC) [Internet]. American Speech-Language-Hearing Association; 2019. Available from: https://www.asha.org/public/ speech/disorders/AAC/.

[2] UN. Universal Declaration of Human Rights [Internet]. Vol. 2018. United Nations; 1948. Available from: http://www.un. org/en/documents/udhr/index.shtml.

[3] UN. Convention on the Rights of Persons with Disabilities [Internet]. UN; 2007. Available from: http://www.un.org/ disabilities/default.asp?id=150.

[4] Statistics Sweden. ICT usage in households ICT usage in households and by individuals [Internet]. Statistics Sweden; 2018 [cited 2019 Oct 4]. Available from: https://www.scb.se/ en/finding-statistics/statistics-by-subject-area/living-conditio ns/living-conditions/ict-usage-in-households-and-by-individ uals/.

[5] Jaeger PT. Disability and the Internet. Boulder, Colorado: Lynne Rienner Publishers Inc.; 2012.

[6] McNaughton D, Light J. The iPad and mobile technology revolution: Benefits and challenges for individuals who require augmentative and alternative communication. Augment Altern Commun [Internet]. 2013; 29(2): 107-16. Available from: http://www.ncbi.nlm.nih.gov/pubmed/23705813.

[7] Beukelman DR, Mirenda P. Augmentative and Alternative Communication Processes. 4th ed. Augmentative and alternative communication. Supporting children and adults with complex communication needs. Baltimore, MD: Paul $\mathrm{H}$ Brookes Publishing Co.; 2013.

[8] Higginbotham DJ, Shane H, Russell S, Caves K. Access to AAC: Present, past, and future. Augment Altern Commun [Internet]. 2007/08/21. 2007; 23(3): 243-57. Available from: http://www.ncbi.nlm.nih.gov/entrez/query.fcgi?cmd=Retrieve $\& \mathrm{db}=$ PubMed\&dopt=Citation\&list_uids $=17701743$.

[9] Light J, McNaughton D. Supporting the communication, language, and literacy development of children with complex communication needs: State of the science and future research priorities. Assist Technol [Internet]. 2012/05/18. 2012; 24(1): 34-44. Available from: http://www.ncbi.nlm.nih.gov/entrez/ query.fcgi?cmd=Retrieve $\& \mathrm{db}=\mathrm{PubMed} \& \mathrm{dopt}=$ Citation $\&$ list _uids $=22590798$.

[10] Buchholz M, Ferm U, Holmgren K. "That is how I speak nowadays" - experiences of remote communication among persons with communicative and cognitive disabilities. Disabil Rehabil [Internet]. 2018 Jun 5; 40(12): 1468-79. Available from: doi: 10.1080/09638288.2017.1300340.

[11] Hynan A, Goldbart J, Murray J. A grounded theory of Internet and social media use by young people who use augmentative and alternative communication (AAC). Disabil Rehabil [Internet]. 2015; 37(17): 1559-75. Available from: http:// www.ncbi.nlm.nih.gov/pubmed/26087813.

[12] Johansson S, Gustavsson C, Gulliksen J. Svenskarna med funktionsnedsättning och internet: Användning av internet. Rapport till Post-och telestyrelsen och Konsumentverket. [Internet]. Begripsam, KTH och Post-och Telestyrelsen; 2018. Available from: http://pts.se/sv/dokument/rapporter/internet/ 2018/undersokningen-svenskarna-med-funktionsnedsattningoch-internet/.

[13] Chadwick D, Wesson C, Fullwood C. Internet access by people with intellectual disabilities: Inequalities and opportunities. Future Internet. 2013; 5(3): 376-397. doi: 10.3390/fi50 30376.

[14] Caron JG, Light J. Social media experiences of adolescents 
and young adults with cerebral palsy who use augmentative and alternative communication. Int J Speech Lang Pathol [Internet]. 2017; 19(1): 30-42. Available from: http://www.ncbi. nlm.nih.gov/pubmed/27063698.

[15] Raghavendra P, Newman L, Grace E, Wood D. Enhancing social participation in young people with communication disabilities living in rural Australia: Outcomes of a home-based intervention for using social media. Disabil Rehabil [Internet]. 2015; 37(17): 1576-90. Available from: doi: 10.3109/09638 288.2015.1052578.

[16] Buchholz M, Müller IM, Ferm U. Text messaging with pictures and speech synthesis for adolescents and adults with cognitive and communicative disabilities-professionals' views about user satisfaction and participation. Technol Disabil. 2013; 25(2): 87-98.

[17] Alfredsson Ågren K, Kjellberg A, Hemmingsson H. Digital participation? Internet use among adolescents with and without intellectual disabilities: A comparative study. New Media Soc. 2019. doi: 10.1177/1461444819888398.

[18] Ryan RM, Deci EL. Self-determination theory and the facilitation of intrinsic motivation, social development, and wellbeing. Am Psychol [Internet]. 2001/06/08. 2000; 55(1): 6878. Available from: http://www.ncbi.nlm.nih.gov/entrez/ query.fcgi? $\mathrm{cmd}=$ Retrieve $\& \mathrm{db}=$ PubMed \&dopt=Citation \&list _uids $=11392867$.

[19] WHO. International Classification of Functioning, Disability and Health [Internet]. Vol. 2018. World Health Organization; 2001. Available from: http://www.who.int/classifications/icf/ en.

[20] Light J, McNaughton D. Communicative competence for individuals who require augmentative and alternative communication: A new definition for a new era of communication? Augment Altern Commun. 2014; 30(1): 1-18.

[21] Owuor J, Larkan F, MacLachlan M. Leaving no-one behind: Using assistive technology to enhance community living for people with intellectual disability. Disability and Rehabilitation: Assistive Technology. 2017 Jul; 12(5): 426-428. doi: 10.1080/17483107.2017.1312572.

[22] Kurt S. Moving toward a universally accessible web: Web accessibility and education. Assist Technol [Internet]. 2017; 1 10. Available from: http://www.ncbi.nlm.nih.gov/pubmed/ 29219749.

[23] Hemsley B, Balandin S, Palmer S, Dann S. A call for innovative social media research in the field of augmentative and alternative communication. Augment Altern Commun [Internet]. 2017; 33(1): 14-22. Available from: doi: 10.1080/07434 618.2016.1273386.

[24] McNaughton D, Bryen D, Blackstone S, Williams M, Kennedy P. Young adults with complex communication needs: Research and development in AAC for a "diverse" population. Assist Technol [Internet]. 2012/05/18. 2012; 24(1): 45-53. Available from: http://www.ncbi.nlm.nih.gov/entrez/ query.fcgi? $\mathrm{cmd}=$ Retrieve $\& \mathrm{db}=$ PubMed $\&$ dopt $=$ Citation $\&$ list _uids=22590799.

[25] Paterson HL. The use of social media by adults with acquired conditions who use AAC: Current gaps and considerations in research. Augment Altern Commun [Internet]. 2017; 33(1): 23-31. Available from: doi: 10.1080/07434618.2016.12757 89.
[26] Palmer SB, Wehmeyer ML, Davies DK, Stock SE. Family members' reports of the technology use of family members with intellectual and developmental disabilities. J Intellect Disabil Res. 2012; 56(4): 402-414. doi: 10.1111/j.1365-2788. 2011.01489.x.

[27] Näslund R, Gardelli A. "I know, I can, I will try": Youths and adults with intellectual disabilities in Sweden using information and communication technology in their everyday life. Disabil Soc. 2013; 28(1): 28-40. doi: 10.1080/09687599. 2012.695528.

[28] Kitzinger J, Barbour R. Introduction: the challenge and promise of focus groups. In: Barbour R, Kitzinger J, eds. Developing focus group research Politics, theory and practice. London: Sage Publications; 1999. pp. 1-20.

[29] Krueger RA, Casey MA. Focus Groups: A Practical Guide for Applied Research. 5th ed. California: SAGE Publications, Inc; 2015. 252.

[30] Dahlin Ivanoff S, Hultberg J. Understanding the multiple realities of everyday life: Basic assumptions in focus-group methodology. Scand J Occup Ther. 2006; (13): 125-32.

[31] Newman L, Browne-Yung K, Raghavendra P, Wood D, Grace E. Applying a critical approach to investigate barriers to digital inclusion and online social networking among young people with disabilities. Inf Syst J. 2017; (27): 559-588.

[32] Todman J, Alm N. Modelling conversational pragmatics in communication aids. J Pragmat. 2003; 35: 523-38.

[33] Mattsson Müller I, Buchholz M, Ferm U. Text messaging with picture symbols - Experiences of seven persons with cognitive and communicative disabilities. J Assist Technol [Internet]. 2010; 4(4): 11-23. Available from: http://pierprofession al.metapress.com/content/v46381v76071/?p=78d8a16b5da0 437f8662ec62028094cb\&pi $=0$.

[34] W3C. Web Content Accessibility Guidelines (WCAG) Overview [Internet]. Vol. 2018. W3C; 2018. Available from: https://www.w3.org/WAI/intro/wcag.

[35] Blackstone SW, Williams MB, Wilkins DP. Key principles underlying research and practice in AAC. Augment Altern Commun [Internet]. 2007/08/21. 2007; 23(3): 191-203. Available from: http://www.ncbi.nlm.nih.gov/entrez/query. fcgi?cmd=Retrieve $\& \mathrm{db}=$ PubMed $\&$ dopt=Citation\&list_uids $=$ 17701739.

[36] AEGIS - Open Accessibility Everywhere [Internet]. Vol. 2018. Available from: http://www.aegis-project.eu/.

[37] Buchholz M, Ferm U, Holmgren K. Support persons' views on remote communication and social media for people with communicative and cognitive disabilities [published online ahead of print, 2018 Nov 28]. Disabil Rehabil. 2018. 1-9. doi: 10.1080/09638288.2018.1529827.

[38] Buchholz M, Ferm U, Holmgren K. Digital Communication and Social Media for People with Communicative and Cognitive Disabilities. In: Hayre C (Ed.), Muller D (Ed.), Scherer M (Ed.). (2020). Everyday Technologies in Healthcare. Boca Raton; 2019. CRC Press, doi: 10.1201/9781351032186. 